\title{
Tracer monitoring of enhanced oil recovery projects
}

\author{
$\varnothing$. Dugstad, S. Viig, B. Krognes, R. Kleven and O. Huseby \\ Institute for Energy Technology, PO Box 40, 2027 Kjeller, Norway
}

\begin{abstract}
In enhanced oil recovery (EOR), chemicals are injected into the oil reservoir, either to increase macroscopic sweep efficiency, or to reduce remaining oil saturation in swept zones. Tracers can be used to identify reservoirs that are specifically suited for EOR operations. Injection of a selection of partitioning tracers, combined with frequent sample analysis of produced fluids, provides information suited for estimation of residual oil saturation. Tracers can also be used to evaluate and optimize the application of EOR chemicals in the reservoir. Suitable tracers will follow the EOR chemicals and assist in evaluation of retention, degradation or trapping. In addition to field applications, tracers also have a large potential as a tool to perform mechanistic studies of EOR chemicals in laboratory experiments. By labelling EOR chemicals with radioactive isotopes of elements such as H, C and S, detailed studies of transport mechanisms can be carried out. Co-injection of labelled compounds in dynamic flooding experiments in porous media will give information about retention or separation of the unique compounds constituting the chemical formulation. Separation of such compounds may be detrimental to obtaining the EOR effect expected. The paper gives new information of specific methods, and discusses current status for use of tracers in EOR operations.
\end{abstract}

\section{INTRODUCTION}

As the world's oil fields are maturing, enhanced oil recovery (EOR) is becoming increasingly important to secure supplies of oil. In EOR operations a range of chemicals are used, e.g, injection of alkaline solutions, polymers, surfactants, as well as combinations of these [1-6]. Other techniques use low salinity water, foam, nanoparticles that react to block larger pores and microbial reactions MEOR (see [7,8] for recent reviews). One of the challenges in EOR-operations is to quantify the potential for producing remaining oil and to evaluate the effect of EOR measures, often done using pilot studies. One of the technologies available to estimate the potential for EOR and the effect of EOR is tracer technology. Several different tracer technologies are available to monitor secondary and tertiary production. Injection of water as well as gas is often monitored by using tracers that follow the injected phase as passively as possible in socalled inter-well tracer tests (IWTT). IWTT are becoming a standard method in the oil industry and has recently been reviewed by e.g. Dugstad [9]. In the present article we will review our own recent work regarding tracer testing of EOR-operations. In particular we will focus on the partitioning inter-well tracer test (PITT), radioactive labelling of EOR-chemicals and the use of tracers to monitor polymer flooding.

An important technology used to estimate the amount of oil in a reservoir is the single-well chemical tracer test (SWCTT). It exploits the difference in travel time between injected ester and alcohol generated in-situ by hydrolysis and was pioneered in the US about 40 years ago by Esso $[10,11]$. SWCTTs have been used to identify enhanced oil recovery (EOR) potential as well as to evaluate the effect of EOR in numerous on-shore fields [12] and some off-shore locations [13-15]. Recently there has been a growing interest in injection of low-salinity water to reduce remaining oil saturation and enhance oil production. Several pilot tests have been conducted and the
SWCTT is used in these projects to measure oil-saturation prior to and after the low-salinity water injection [13-16]. On the Norwegian continental shelf two pilot-tests have been conducted recently, in the Snorre-field [15] and in the Heidrun-field.

An alternative to SWCTTs for measuring oil saturations is the partitioning interwell tracer test (PITT) $[9,17]$. In contrast to the SWCTT, PITTs have been used to a limited extent in the petroleum industry (see $[18,19]$ for some exceptions). On the other hand PITTs have been used successfully to estimate non-aqueous phase liquid content in several groundwater remediation projects $[17,20]$. In several of the reported PITT projects different alcohols have been used as chemical tracers, with detection limits in the order of ppm concentrations. This is too high in many large scaled reservoirs relevant for the oil industry. In large reservoirs tracers are significantly diluted and sub-ppb concentrations are necessary to keep injected tracer amounts within reasonable limits. In addition, it is important that the tracer chemicals are stable and reliable in the harsh conditions found in most oil reservoirs. New chemicals that can meet these limitations are currently being tested. In this review we illustrate how these chemicals can be tested in laboratory experiments. This is done using butanol, which is one of the PITT tracers currently available. We also show results from a PITT in an oilfield and point to potential problems using butanol as partitioning tracer.

In a second example we demonstrate how labelling of EOR chemicals can help to understand and optimise EOR-processes. In the particular example the hydrogen isotope tritium $\left({ }^{3} H\right)$ is used to label water, the sulphur isotope ${ }^{35} \mathrm{~S}$ is used to label surfactants and the ${ }^{14} \mathrm{C}$-isotope is used to label $\mathrm{CO}_{2}$ in a $\mathrm{CO}_{2}$-foam experiment.

In the final experimental example we demonstrate how conventional water tracers can be used to evaluate water flooding in porous media when polymers are used to modify sweep. 


\section{PARTITIONING INTER-WELL TRACER TESTING}

The partitioning inter-well tracer test to determine residual oil saturation is based on chromatographic separation of tracers in the reservoir. In a PITT, tracers with different oil/water partition coefficients are introduced with the injection water, and samples of water are collected from the production stream for analysis. The tracer with the highest partition coefficient will lag behind other tracers. The delay of the partitioning tracer depends on the partition coefficient as well as the oil saturation in the volume between injector and producer wells. This dependency is used to measure the oil saturation in the reservoir.

If we assume that partitioning among the phases is an instantaneous process a conservation equation for an arbitrary partitioning tracer component may be written as [21]

$$
\begin{aligned}
& \frac{\partial}{\partial t}\left(\sum_{i=o, g, w} \varphi K_{i} S_{i} C\right)+\nabla \cdot\left(\sum_{i=o, g, w} \boldsymbol{v}_{i} K_{i} C\right) \\
& -\nabla \cdot\left(\sum_{i=o, g, w} \varphi S_{i} \boldsymbol{D}_{i}^{*} \cdot \nabla\left(K_{i} C\right)\right)=0 .
\end{aligned}
$$

Here, partitioning is described by the coefficient $K_{i}=$ $C_{i} / C$, where $C_{i}$ is the concentration in phase $i$ and $C$ is the concentration in a reference phase. For oil/water partitioning with water as the reference phase, this gives $K_{o}=C_{o} / C$ and $K_{w}=C_{w} / C=1$. Furthermore in Equation (1), $\varphi$ is porosity, $S_{i}$ is phase saturation $\left(S_{o}, S_{g}\right.$ or $\left.S_{w}\right), v_{i}$ is the velocity of phase $i$ and $\boldsymbol{D}_{i}^{*}$ is the dispersion in phase $i$. The dispersion is a tensor quantity with different components $D_{n}^{*}$ along and $D_{p}^{*}$ normal to the flow. In porous media dispersion is well described by

$$
\frac{D_{n}^{*}}{D_{m}}=\frac{1}{\tau}+\beta_{n} N_{P e}^{\alpha_{n}} \quad \frac{D_{p}^{*}}{D_{m}}=\frac{1}{\tau}+\beta_{p} N_{P e}^{\alpha_{p}}
$$

where $\tau$ is the tortuosity of the porous medium and the $\alpha$ and $\beta$ coefficients depend on the media. The Peclet number is given from velocity, molecular diffusion coefficient and grain size by $N_{P e}=v d / D_{m}$.

In a water-flooded area, close to residual oil saturation oil, flow rates may be negligible compared to the water flow rates. In such cases oil saturation may be determined by differences in retention times of a partitioning and passive water tracer. Oil saturation is given by the simple expression

$$
S=\frac{\left(t_{2}-t_{1}\right)}{\left(t_{2}+t_{1}\left(K_{o}-1\right)\right)} .
$$

Here $t_{1}$ and $t_{2}$ are the retention times of the nonpartitioning and partitioning tracer, respectively, $S$ is the residual oil saturation, and $K_{o}$ is the partition coefficient of the partitioning tracer. If $K_{o}$ is known, the residual oil saturation can be calculated from the measured difference in the arrival times between a non-partitioning (passive) and a partitioning tracer.

To demonstrate the PITT concept on the laboratory scale consider a dynamic flooding experiment where a partitioning tracer $\left({ }^{14} \mathrm{C}\right.$ labelled n-butanol) and an ideal

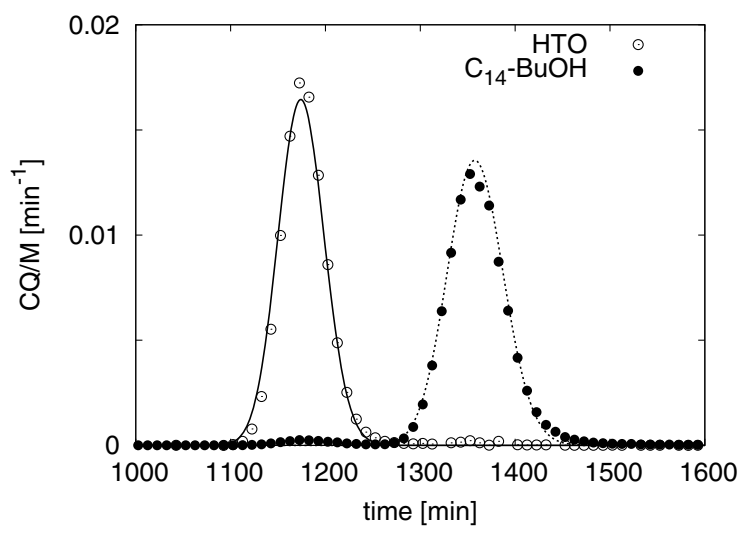

Figure 1. Experimental concentrations (symbols) and analytic solutions (solid and dotted lines) from Equation (6) of HTO and ${ }^{14} \mathrm{C}$ labeled $\mathrm{n}$-butanol in a one-dimensional system with $14.8 \%$ residual oil saturation. The $\mathrm{K}$-value of $\mathrm{n}$-butanol in this experiment was calculated to $\mathrm{K}=0.9$.

tracer (tritiated water, HTO) was injected in a column filled with Clashack sand. The column has a porosity of $44 \%$ and was prepared with a residual oil saturation of $14.8 \%$. In the experiment dead crude oil from the Ekofisk field was used and the temperature was $90^{\circ} \mathrm{C}$. The partition coefficient for $\mathrm{n}$-butanol obtained from the experiment was $K_{o}=0.9$ at $90{ }^{\circ} \mathrm{C}$. The column length was $L=2 \mathrm{~m}$, the diameter was $d=1.11 \mathrm{~cm}$ and water was injected with a flow rate $Q_{w}=0.062 \mathrm{ml} / \mathrm{min}$ from below in the vertical oriented column.

This experiment can be analysed by means of an analytic solution. Briefly, in this case Equation (1) can be written as [21]

$$
\frac{\partial C}{\partial t}+v^{*} \frac{\partial C}{\partial x}-D^{*} \frac{\partial^{2} C}{\partial x^{2}}=0
$$

where $v^{*}$ and $D^{*}$ are effective velocity and dispersion. The effective velocity $v^{*}$ is a combination of saturation, partitioning and the velocity of tracer in the water phase, $v^{*}=$ $v_{w}(1-S) /(K S+1-S)$. The effective dispersion is a combination of the dispersion in oil and water phase, $D^{*}=$ $\left((1-S) D_{w}^{*}+K S D_{o}^{*}\right) /(K S+1-S)$. Equation (4) is a 1-D convection diffusion equation. With initial and boundary conditions

$C(x=0, t)=\frac{M}{Q} \delta(t), C(x, t=0)=0, \lim _{x \rightarrow \infty} C(x, t)=0$

it has the solution [22]

$$
C(L, t)=\frac{M}{Q} \frac{L}{\sqrt{\left(4 \pi D^{*} t^{3}\right)}} \exp \left[-\frac{\left(L-v^{*} t\right)^{2}}{4 D^{*} t}\right]
$$

at $x=L$. Equation (6) for HTO and n-butanol are plotted together with the experimental data in Figure 1, and corresponds well to the experimental data.

From Equation (6) we can find the time corresponding to arrival of the peak at $\mathrm{L}$. The solution has a maximum value at $L=v^{*} t$, which yields $t_{1}=L / v_{w}$ for the nonpartitioning tracer and $t_{2}=L / v_{w} \cdot\left(K_{2} S+1-S\right) /(1-S)$ for the partitioning tracer. By simple algebraic 


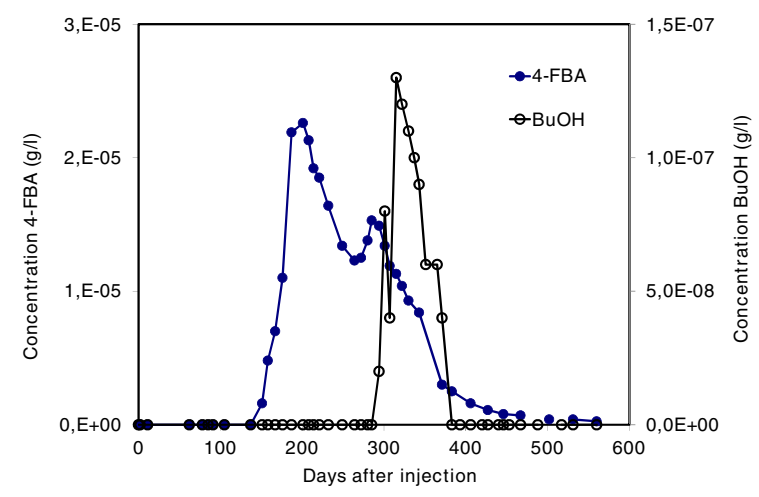

Figure 2. Tracer curves for a passive (4-FBA) and partitioning $(\mathrm{BuOH})$ tracer in an on-shore oil field. The passive 4-FBA tracer arrives approximately five months before the perdeuterated butanol tracer. A large degree of degradation of the butanol tracer was observed, corresponding to a $99 \%$.

manipulations we then obtain the relation in Equation (3) between peak arrival times and saturation.

The PITT technology was also recently tested in an onshore field close to residual oil saturation. A field-proven non-partitioning 4-FBA (4-fluorobenzoic acid) tracer was co-injected with perdeuterated butanol. The production curves for the 4-FBA tracer and the partitioning butanol tracer are given in Figure 2. The measured concentrations of perdeuterated butanol were two orders of magnitude lower than the concentrations of 4-FBA (note that separate scales are used in Figure 2. The large loss (approx. $99 \%$ ) of the partitioning tracer is possibly due to thermal or biological degradation or adsorption on the reservoir rocks. Nevertheless, the obtained production curves for the partitioning tracer show a reasonable delay compared to the ideal tracer and yielded saturations as expected by simulations of the reservoir flow.

Due to the instability of perduterated butanol in the field test, a suit of other partitioning organic molecules have been developed and tested in laboratory experiments. One of these components, denoted by the trade name IFE-WTP shows high degrees of stability and all the compounds can be analysed in concentrations down to $50 \mathrm{ppt}$. Field testing of these components are currently underway.

\section{TRACERS TO EVALUATE $\mathrm{CO}_{2}$-FOAM}

Different types of oil reservoirs have been flooded by carbon dioxide $\left(\mathrm{CO}_{2}\right)$, see e.g., $[1,2,23,24]$. Some few examples report the use of perfluorocarbons as tracers for $\mathrm{CO}_{2}$ [25]. Microscopic sweep efficiency in EOR $\mathrm{CO}_{2}$ floods can be high, but macroscopic sweep efficiency (EMA) can still be low due to combination of high mobility ratio, gravity segregation and heterogeneity [26-29]. By reducing the mobility of $\mathrm{CO}_{2}$, EMA can be improved. Such mobility reduction can be obtained either by co-injection a polymer or by creating a $\mathrm{CO}_{2}$ foam.

Foam is usually generated with the aid of surfactants [30-32]. Surfactants, such as alpha olefin sulphonate (AOS), have been used as $\mathrm{CO}_{2}$ foaming agent. Depending

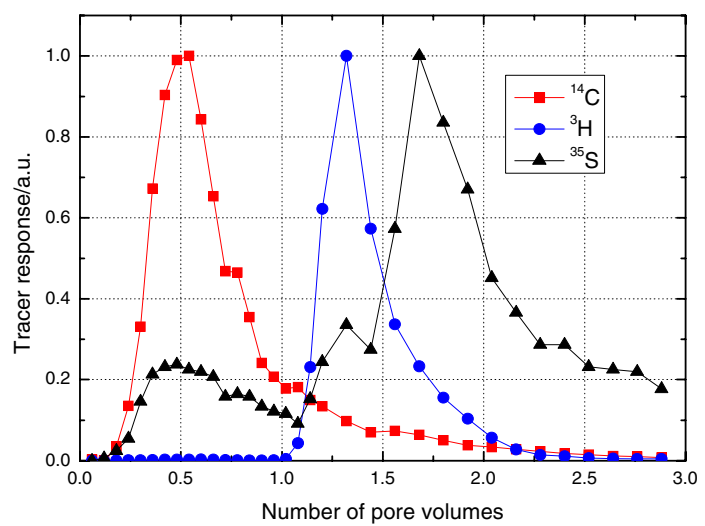

Figure 3. Retention time of $\mathrm{HTO},{ }^{14} \mathrm{CO}_{2}$ and ${ }^{35} \mathrm{~S}$ labelled AOS when transported through a porous column.

on foam stability and porous structure the components constituting the foam, gas (dense $\mathrm{CO}_{2}$ phase), water, and surfactants, may travel with different velocities through the porous network [33-36]. Dynamic flooding experiments have been carried out at realistic reservoir conditions to study the relative transport of water, $\mathrm{CO}_{2}$ and surfactant when foam is generated in the porous network [37]. The surfactant was labelled with the radioactive sulphur isotope ${ }^{35} \mathrm{~S}$. The water has been labelled with the radioactive hydrogen isotope tritium $\left({ }^{3} \mathrm{H}\right)$ and the $\mathrm{CO}_{2}$ has been labelled with the ${ }^{14} \mathrm{C}$ isotope.

It was shown that the flow of the individual phases in a $\mathrm{CO}_{2}$-foam flooding can be monitored by using this tracer technology (Fig. 3). Variations in the flow rates of surfactant components, water (HTO) and $\mathrm{CO}_{2}$ can be clearly detected, and the accessible pore volume can also be determined. Commercially available AOS products contain different chemical components. In the study, the main AOS components were chemically separated prior to injection on the porous column. The labelling technique allows studies of retention time of the different components when these have been injected as a sharp pulse in a steady state, foam filled porous column. The transport of the individual components was shown to be different. In the reservoir, such chromatographic separation of the AOS components may affect the efficiency of the foam process.

\section{TRACERS TO MONITOR POLYMER FLOODING}

Polymers can be used to improve the macroscopic sweep efficiency in a water flood by increasing the viscosity of the displacement fluid. A review of 12 polymer floods in the period 1975-1992 is given in [38]. Recently, there has been an increased interest in polymer flooding [39-42]. As for the other EOR-applications reviewed in this paper, tracers can be used to monitor polymer floods. If a passive tracer is co-injected continuously with the EOR chemicals information about flow direction, degree of retention and dilution of actual EOR chemicals can be obtained. By tracer curve analysis of the tracer response of a tracer injected as a narrow pulse the sweep before and after the polymer flood can be found [47]. Changes in swept 


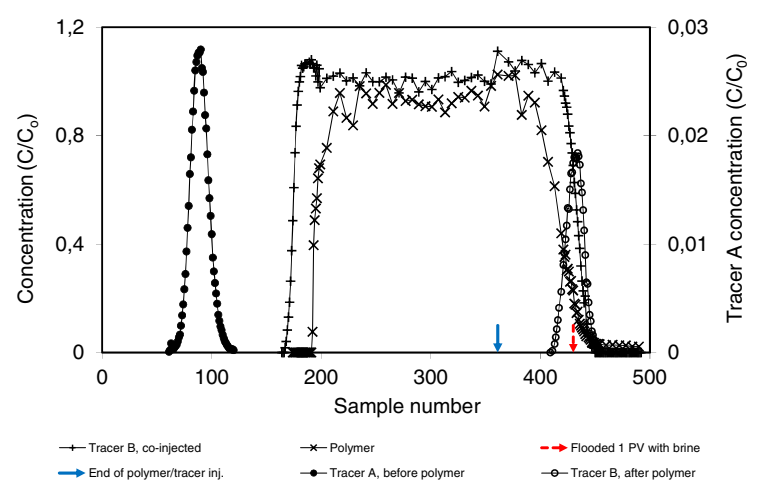

Figure 4. Experimental results for tracers and polymer in a polymer flooding experiment. Concentrations of tracer A injected as a pulse before and a pulse after the polymer flood are given as full and open circles, respectively. Concentrations of Tracer B (crosses), co-injected continuously with the polymer and polymer concentrations (x-symbols) are also given.

volume caused by the chemical EOR operation can thus be monitored. Both for continuous and pulse injection reliable passive water tracers are required. To qualify dynamic properties of tracers mixed with EOR chemicals and verify that they are suited for polymer applications, 15 tracers were identified and investigated. In the following one of these tracers is studied in dynamic experiments and the results are compared to results obtained using the ideal tracer, tritiated water (HTO).

From dynamic polymer flooding experiments (using a Flopaam $3630 \mathrm{~S}$ polymer) it was observed that the 15 tracers gave responses equal within a few percent to the HTO reference tracer under the given experimental conditions. Results for HTO injected continuously and pulse injections of one of the chemical tracers before and after the polymer flood are summarized in Figure 4.

The observed deviation between the HTO tracer response and the polymer clearly shows that the passive tracer and the polymer are transported in the porous media in different ways. The polymer breaks through after the continuously, co-injected HTO tracer and a steeper slope in the polymer response curve than the tracer response curve is observed. A numerical sensitivity study shows that this effect is caused by adsorption of the polymer in the front due to saturation of the surface of the silica sand. Adsorption slows the breakthrough of the polymer in this case. The adsorption can also explain the tailing seen in the polymer results. Polymer adsorbed to the surface desorbs slowly and acts as a source term for polymer that prevails for some time after the passing of the tracer and polymer slug. Other studies show that in some cases polymer can be transported faster than tracers through the porous medium [43]. The reason for this is that other effects compete with polymer adsorption in some cases. In other solid matrices, e.g., some pores may be inaccessible for the polymer transport due to polymer molecules blocking parts of the pore space.

In addition to the continuously injected HTO tracer, a tracer (denoted Tracer A) was pulse-injected before and after the polymer flooding (cf. Fig. 4). To qualify this tracer, HTO was also pulse-injected prior to the polymer

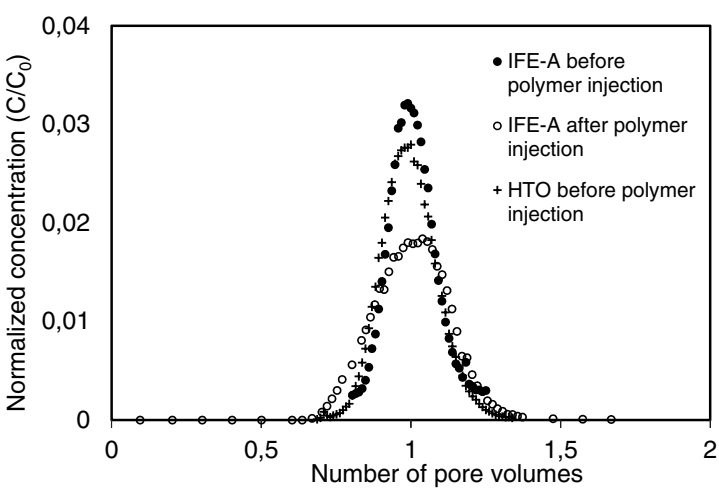

Figure 5. Tracer response from pulse injection before and after polymer flooding as a function of PV flooded after injection of the tracers. The ideal tracer HTO is used to qualify the Tracer A.

flood. The curves for HTO and Tracer A before the polymer flood differed slightly in peak values and widths (cf. Fig. 5). The difference between HTO and Tracer A before the polymer flooding is due to different diffusion coefficients. In Figure 5 the response curves for Tracer A after the polymer flooding is also given. Interestingly, the response curve for Tracer $\mathrm{A}$ is broader and with a smaller peak-value after polymer flooding, than before. As this is the same tracer, with similar diffusion coefficient, it is likely that the curve-difference is due to modifications of the geometry that manifest themselves as changes to the dispersion function. Changes to the dispersion can be caused by adsorption of polymer in the sand-pack.

\section{SIMULATION OF EOR TRACERS}

Since tracers do not influence fluid flow in the reservoir, tracer transport may be solved in a separate module decoupled from the reservoir simulation itself. This was exploited in [44] to solve for tracer transport using fluid flow solutions obtained from a reservoir fluid flow simulation. In [44] the flow field was retrieved from the host reservoir simulator at each time-step, and then used to find tracer flow simultaneously with solving the fluid flow. This modular method allows coupling to any black oil simulator used in most cases or compositional simulators relevant for EOR. It also allows for a separate time and space discretization of the tracer equation, which was used in [44] to obtain accurate solutions. Although the method of [44] is more flexible than most tracer simulation methodologies, it shares a subtle drawback with commonly used tracer simulation approaches. If tracer simulation is performed simultaneously with the reservoir simulation, re-performing the tracer simulation requires re-performing the reservoir simulation. This is a serious disadvantage if lessons-learned from a first tracer simulation are to be applied in subsequent tracer simulations. The simple solution to this is to store solutions to the reservoir fluid flow problem for each reservoir simulation time-step, and perform the tracer simulation based on the stored results $[45,46]$. Multiple and successive tracer simulations can then be performed based on stored results from a single reservoir simulation. The tracer simulation is very 


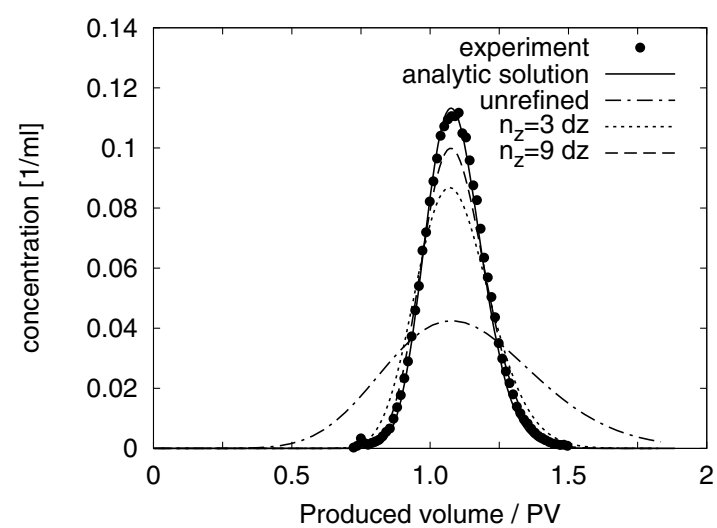

Figure 6. Tracer concentrations for HTO prior to polymer injection in the experiment in Section 4, compared to an analytic solution similar to Equation (6), and numerical solutions obtained with several refinements in the time-step and tracer-grid.

fast, compared to the reservoir simulation, with typically execution times in the order of $1-5 \%$ of the reservoir simulation. Significant amounts of time can thus be saved using this approach. One application of the decoupling of flow and tracer solution is successive refinement of discretization grid to counter numerical smearing of the tracer solutions. Smearing of the numerical solution occurs both for saturation fronts and tracer fronts, but are particularly severe when solving the transport equations for tracer pulse injections. To improve on this situation, one can use successively finer time-steps and a separately refined tracer-grid. The method described in [46] allows for successive refinement of the tracer time and space discretization, at the cost of a single reservoir simulation. Since the tracer transport is separated from the flow problem solved by the host reservoir simulator, a smaller time-step and refined grid can be used without affecting the reservoir simulator. The method was used to obtain solutions for the tracer flow in the experiment described in Section 4. The results from these simulations are displayed in Figure 6. From Figure 6 it is clear that decreasing the tracer grid size significantly improves the numerical solution. The numerical solutions approach the analytical solution and the measured results.

\section{CONCLUSIONS}

The use of tracers is an important method in the reservoir engineering tool box. Besides the standard methods used for following water and gas flood in secondary recovery operations, tracers are also very useful in tertiary recovery and EOR operations. In this paper we have reviewed how partitioning inter-well tracer tests can be used to establish oil saturations in water flooded regions prior to EOR operations. We have also discussed how tracers can give information on sweep changes due to injection of polymers, and given examples of radiolabelling of EOR-chemicals, to trace their behaviour during EOR. We conclude that tracer methods are powerful tools to monitor phase transport in various chemical flooding scenarios, but emphasize that tracers need to be qualified in order to ensure that they behave as passive tracers during EOR operations. This is not obvious, given the large concentrations or EOR-chemicals used in most EOR-operations. Labelling of individual components, by radioactive isotopes, gives unique possibilities to follow special organic chemicals used in EOR processes. Although possibly too expensive to be applied in full-field tests, these methods are certainly well suited for laboratory tests and perhaps even in small scale pilot studies. We also illustrated the advantages of solving tracer transport separately from the fluid flow. Separate solution of the tracer problem gives an opportunity to state and solve the tracer problem from pre-solved and stored flow solutions, saving significant CPU-time and allowing for accurate solutions through separate tracer grid refinement.

\section{References}

[1] Taber, J.J., Martin, F.D. and Seright, R.S. 1997a. EOR-screening criteria revisited - part 1: Introduction to screening criteria and enhanced recovery field projects. SPE Reservoir Eng. 12 (3): 189-198

[2] Taber, J.J., Martin, F.D. and Seright, R.S. 1997b. EOR-screening criteria revisited - part 2: Application and impact of oil prices. SPE Reservoir Eng. 12 (3): 199-205

[3] Hernandez C., Chacon L., Anselmi L., Angulo R., Manrique E., Romero E., de Audemard N., Carlisle C.: Single Well Chemical Tracer Test to Determine ASP Injection Efficiency at Lagomar VLA-6/9/21 Area, C4 Member, Lake Maracaibo, Venezuela. SPE/DOE Improved Oil Recovery Symposium, 13-17 April 2002, Tulsa, Oklahoma

[4] Zainal S., Manap A.A.A., Hamid P.A., Othman M., Chong M.O., Yahya A.W., Darman N., Sai R.M.: Offshore Chemical EOR: The Role of an Innovative Laboratory Program in Managing Result Uncertainty to Ensure the Success of a Pilot Field Implementation. SPE paper 113154. EUROPEC/EAGE Conference and Exhibition, 9-12 June, Rome, Italy, 2008

[5] Oyemade, S., Al Harty, S., Jaspers, H., van Wunnik, J., de Kruijf, A. and W.M., S.: Alkaline-surfactant polymer flood: Single well chemical tracer tests design, implementation and performance. SPE 130042, Proc. SPE EOR conference at Oil \& Gas West Asia, Muscat, Oman, 2010

[6] de Zwart A.H., van Batenburg D.W., Stoll M. and Al-Harthi S. Numerical Interpretation of Single Well Chemical Tracer Tests for ASP Injection. 16th European Symposium on Improved Oil Recovery, Cambridge, UK, 12-14 April 2011

[7] Babadagli, T.: Development of mature oil fields - A review, J. Pet. Sci. Eng. 57 (3-4), 221-246 (2007)

[8] Al-Mutairi S.M. and Kokal S.L.: EOR Potential in the Middle East: Current and Future Trends, SPE paper 143287, SPE EUROPEC/EAGE Annual Conference \& Exhibition, Vienna, Austria, 23-26 May 2011

[9] Dugstad Ø. Well-to-Well Tracer Tests, Chapter 6 (pp. 651-683), Petroleum Engineering Handbook, 
Vol. 5 - Reservoir Engineering and Petrophysics by Edward D. Holstein (Ed.) SPE, Richardson, Texas, 2007

[10] Deans H.: Method of determining fluid saturations in reservoirs, US patent \# 3623842, 1971

[11] Deans, H.A.: Using Chemical Tracers to Measure Fractional Flow and Saturation In-situ, SPE 7076, 5th SIMOR of SPE, Tulsa, Oklahoma, 1978

[12] Deans H. and Carlisle C.: The single well chemical tracer test a method for measuring reservoir fluid saturations in-situ. pp. 615-649, Petroleum Engineering Handbook by L.W. Lake (Ed), Vol. 5 Reservoir Engineering and Petrophysics. SPE 2007

[13] Seccombe J.C., Lager A., Webb K., Jerauld G. and Fueg E.: Improving Waterflood Recovery: LoSal $^{\mathrm{TM}}$ EOR Field Evaluation. SPE paper 113480. SPE/DOE IOR Symposium, 20-23 April, Tulsa, USA, 2008

[14] Jerauld G.R., Mohammadi H. and Webb K.J.: Interpreting Single Well Chemical Tracer Tests. SPE paper 129724. SPE Improved Oil Recovery Symposium, 24-28 April, Tulsa, Oklahoma, USA, 2010

[15] Skrettingland K., Holt T., Tweheyo M.T. and Skjevrak I.: Snorre low salinity water injection - core flooding and single well field pilot. SPE 129877, SPE Reservoir Evaluation \& Engineering 14 (2), 182-192 (2011)

[16] McGuire P., Chatham J., Paskvan F., Sommer D. and Carirni F.: Low salinity oil recovery: An exciting new EOR opportunity for Alaska's North Slope. SPE paper 93903, Proc. SPE Western Regional Meeting, Irvin, CA, 2005

[17] Tang J.S.: Extended Brigham Model for Residual Oil Saturation Measurement by Partitioning Tracer Tests SPE paper 84874, SPE Journal 10 (2), 175-183 (2005)

[18] Agca C., Pope G.A., Sepehrnoori K., Modelling and analysis of tracer flow in oil reservoirs, Journal of Petr. Science \& Eng. 4 (1), 3-19 (1990)

[19] Illiassov P.A., Datta-Gupta A.: Field-scale characterization of permeability and saturation distribution using partitioning tracer tests: The Ranger Field, Texas, SPE Journal 7 (4), 409-422 (2002)

[20] Jin M., Jackson R.E., Pope, G.A., Taffinder S.: Development of Partitioning Tracer Tests for Characterization of Nonaqueous-Phase LiquidContaminated Aquifers. SPE paper 39293 SPE Annual Technical Conference and Exhibition, 5-8 October 1997, San Antonio, Texas

[21] Huseby O., Sagen J. and Dugstad $\varnothing .:$ Gas tracer transport - correct formulation and fast postprocessing simulation technique. SPE paper 142991 EUROPEC/ EAGE Annual Conference \& Exhibition, Vienna, Austria, 23-26 May 2011

[22] Lenda, A. and Zuber, A.: "Tracer dispersion in groundwater experiments." In: Isotope Hydrology (Proc. IAEA Symp.), IAEA, Vienna, pp 619-641, 1970
[23] Kovscek, A.R.: Screening criteria for CO2 storage in oil reservoirs. Petroleum Science Tech. 20 (7\&8), 841-866 (2002)

[24] Manrique, E.J., Muci, V.E. and Gurfinkel, M.E. 2006. EOR Field Experiences in Carbonate Reservoirs in the United States. SPE 100063. SPE/DOE Symp. IOR, Tulsa, Oklahoma, U.S.A., 22-26 April

[25] Meer, B. v. d., D. H. Daan, et al. (2006). CO2 Storage and Testing, Enhanced Gas Recovery in the K12-B Reservoir, TNO

[26] Rogers, J.D., and Grigg, R.B.: A Literature Analysis of the WAG Injectivity Abnormalities in the CO2 Process. SPE 73830. SPE Res Eval Eng 4 (5), 375 386 (2001)

[27] Abdassah, D., Siregar, S., and Kristanto, D. 2000. The Potential of Carbon Dioxide Gas Injection Application in Improving Oil Recovery. SPE 64730. SPE 7th Int. Oil and Gas Conf. \& Exhib., Beijing, China, 7-10 Nov.

[28] Harpole, K.J., and Hallenbeck, L.D. 1996. East Vacuum Grayburg San Andres Unit CO2 Flood Ten Year Performance Review: Evolution of a Reservoir Management Strategy and Results of WAG Optimization. SPE 36710. SPE Annual Tech. Conf. \& Exhib., Denver, Colorado, U.S.A., 6-9 Oct.

[29] Jonas, T.M., Chou, S.I., Vasicek, S.L. 1990. Evaluation of a CO2 Foam Field Trial: Rangely Weber Sand Unit. SPE 20468. 55th Annual Tech. Conf. \& Exhib. SPE, New Orleans, LA, U.S.A., 23-26 Sep.

[30] Rossen, W.R., Duijn, C.J. van, Nguyen, Q.P., and Vikingstad, A.K. 2006. Injection Strategies to Overcome Gravity Segregation in Simultaneous Gas and Liquid Injection into Homogeneous Reservoirs. SPE 99794. SPE/DOE Symp. IOR, Tulsa, 22-26 April

[31] Zuta, J., Fjelde, I., and Berenblyum, R.A. 2009. Oil Recovery during CO2-foam Injection in Fractured Chalk Rock at Reservoir Conditions. Int. Symp. Society of Core Analysts, Noordwijk, Netherlands, 26-30 Sep.

[32] Zuta, J., Fjelde, I., and Berenblyum, R.A. 2010. Experimental and simulation of $\mathrm{CO} 2$-foam flooding in fractured chalk rock at reservoir conditions: Effect of mode of injection on oil recovery. SPE-129575, the 2010 SPE EOR Conf. Oil \& Gas West Asia, Muscat, Oman, 11-13 April 2010

[33] Kim, J.S., Dong, Y., and Rossen, W.R. 2004. SteadyState Flow Behavior of CO2 Foam. SPE89351. SPE/DOE Symp. IOR, Tulsa, Oklahoma, U.S.A., 17-21 April

[34] Kovscek, A.R. Patzek, T.W. and Radke, C.J. 1993. Simulation of Foam Transport in Porous Media. SPE 26402. Annual Technical Conference and Exhibition, Houston, Texas, 3-6 October

[35] Friedmann, F., Chen, W.H., Gauglitz, P.A.: Experimental and Simulation Study of High-Temperature Foam Displacement in Porous Media. SPE Reservoir Engineering 6 (1), 37-45 (1991)

[36] Nguyen, Q. P., Alexandrov, A. V., Zitha, P. L. and Currie, P. K. 2000. Experimental and Modelling 
Studies on Foam in Porous Media: A Review. Paper SPE 58799. SPE International Symposium on Formation Damage Control, Lafayette, 23-24 Feb.

[37] Dugstad Ø., Opel K. and Fjelde I.: Improved understanding of CO2/Foam EOR techniques by aid of Tracer Technology. SPE paper 142985, SPE EUROPEC/EAGE Annual Conference and Exhibition Vienna, Austria, 23-26 May 2011

[38] De Bons F. and Braun R.W.: Polymer flooding: Still a Viable IOR Technique, 8th European IOR Symposium, Vienna, Austria

[39] Morel, D., Vert, M., Jouenne, S., Nahas, E (2008): Polymer Injection in Deep Offshore Field: The Dalia Angola Case, SPE Annual Technical Conference and Exhibition, Denver, Colorado, USA, 21-24 September 2008

[40] Wang, D. M., Han, P. H., Shao, Z. B., Hou, W. H., Seright, R. S.: Sweep-improvement options for the Daqing oil field, SPE Reservoir Evaluation \& Engineering 11, 18-26 (2008)

[41] Dass, C., Jain, M. A., Dhawan, A. K., Misra, T. R. (2008): Monitoring of Polymer flood project at Sanand field of India, SPE Indian Oil and Gas Technical Conference and Exhibition, Mumbai, India, 4-6 March 2008

[42] Yan, W., Demin, W., Jun, W., Jiangtao, L., Runtao, Y., Zengyou, D.: New Developments in Production Technology for Polymer Flooding, SPE/DOE Symposium on Improved Oil Recovery, Tulsa, Oklahoma, USA, 20-23 April 2008
[43] Lund, T. Bjørnestad, E.Ø., Staveland, A., Gjøvikli. N.B., Fletcher, A.J.P., Flew, S.G. and Lamb, S.P.: Polymer retention and inaccessible pore volume in North Sea reservoir material. In O.Vikane (Editor), Enhanced Oil Recovery. J. Pet-Sci. Eng. 7, 25-32 (1992)

[44] Sagen, J., Cvetkovic B., Brendesdal, E., Halvorsen, G., You, Y.L., and Bjørnstad, T.: "Reservoir Chemical-Thermal Simulation with Tracers". SPE paper 36921, SPE European Petroleum Conference, Milan, Italy, 22-24 October, 1996

[45] Sagen, J. and Huseby O.: "Tracer Simulation Tool and Method for Simulating Tracers in Sub-Surface Reservoirs". Patent application no. PCT / EP2009/ 057115, European Patent Office, The Hague, Netherlands, 2009

[46] Huseby O., Sagen J., Wangen M., and Viig S.O. (2010). Planning and Interpretation of Offshore-Field Tracer Tests Using Accurate and Refined Tracer Simulations. SPE 139170 paper presented at the 2010 SPE Latin American and Caribbean Petroleum Engineering Conference, 1-3 December 2010, Lima, Peru

[47] Shook G.M., Pope G.A. and Asakawa K. (2009). Determining Reservoir Properties and Flood Performance From Tracer Test Analysis. SPE paper 124614. SPE Annual Technical Conference and Exhibition, 4-7 October 2009, New Orleans, Louisiana 